\title{
Decentralized automatic generation control of interconnected power systems incorporating asynchronous tie-lines
}

\author{
Ibraheem ${ }^{1}$, Naimul Hasan ${ }^{1}$ and Arkan Ahmed Hussein ${ }^{1,2^{*}}$
}

\begin{abstract}
This Paper presents the design of decentralized automatic generation controller for an interconnected power system using PID, Genetic Algorithm (GA) and Particle Swarm Optimization (PSO). The designed controllers are tested on identical two-area interconnected power systems consisting of thermal power plants. The area interconnections between two areas are considered as (i) AC tie-line only (ii) Asynchronous tie-line. The dynamic response analysis is carried out for $1 \%$ load perturbation. The performance of the intelligent controllers based on GA and PSO has been compared with the conventional PID controller. The investigations of the system dynamic responses reveal that PSO has the better dynamic response result as compared with PID and GA controller for both type of area interconnection.
\end{abstract}

Keyword: Automatic generation control; Genetic algorithm; Particle swarm optimization; Ziegler and Nichols method asynchronous tie-line

\section{Introduction}

Modern Power system consists of large number of generating units interconnected by transmission lines. The interconnection of the power systems enhance the stability and become a viable tool to provide the almost uninterruptible power to load canters from generating stations. The two power system areas may be connected through synchronous/asynchronous tie-lines. To provide a good quality of power, the operation of power system must be maintained at the nominal frequency and voltage profile. And it is achieved by controlling of real and reactive powers. A modern power system is divided into a number of control areas and each area is responsible for its own load and power interchanges. If the input-output power balance is not maintained, a change in frequency will occur which it highly undesirable. In modern interconnected power system, automatic generation control (AGC) is used to maintain

\footnotetext{
* Correspondence: aalganabe@gmail.com

'Department of Electrical Engineering, Faculty of Engineering and Technology, Jamia Millia Islamia, New Delhi, India

${ }^{2}$ Department of Electrical Engineering, Engineering College, Tikrit University, Tikrit, Iraq
}

\section{黑 Springer}

(c) 2014 Ibraheem et al.; licensee Springer. This is an Open Access article distributed under the terms of the Creative Commons Attribution License (http://creativecommons.org/licenses/by/4.0), which permits unrestricted use, distribution, and reproduction in any medium, provided the original work is properly credited. the system frequencies and tie-line power flows at the specified nominal values.

The automatic generations control of interconnected power systems has become more significant as size and complexity of the system is going on increasing to meet out power demand. A large number of control techniques have been proposed by the researchers for the design of AGC regulators. In the early era, the AGC strategies were proposed base on centralized control strategy (Quazza 1966; Elgerd \& Fosha 1970; Aldeen \& Trinh 1994; Fosha \& Elgerd 1970). The limitation of AGC centralized control strategy is that it requires the exchange of information from control areas spread over distantly connected geographical areas along with their increased computational and storage complexities. The decentralized automatic generation control strategies deals the limitations of centralized power system very effectively (Kawabata and Kido 1982; Park \& Lee 1984; Calovic 1984; Aldeen and Marsh 1990,1991; Aldeen 1991; Yang et al. 1998,2002). The researchers (Kumar et al. 1985) proposed the systematic distributed control design methods and achieved almost identical results 
as obtained with the centralized strategies. The design of decentralized load frequency controllers based on structured singular values and multiple controlstructure constraints are discussed in (Kumar et al. 1987; Shayeghi et al. 2007). The decentralized AGC regulator design based on the structured singular value is designed for local area robust analysis, and an eigen value method is derived for tie-line robustness analysis (Tan \& Zhou 2012). (Tan 2011) proposed a method to analyze the stability of multi-area power system by accounting the inherent structure of the multi-area power system. (Sudha and Vijaya Santhi 2011) proposed a Type 2 Fuzzy controller for decentralized two area interconnected power system with consideration of generation rate constraint.

\section{Power system models}

In this paper two power system models are considered for design of decentralized AGC regulators using PID, GA and PSO. The area interconnection in one power system model is only AC tie line and in the second model Parallel AC/DC link is considered

\section{State space model}

The linear time-invariant state space representation of interconnected power system is given by the following equations:

$$
\begin{aligned}
& \dot{X}=A X+B U+\Gamma D \\
& Y=C x
\end{aligned}
$$

Where $\mathrm{A}, \mathrm{B}, \Gamma$ are system, control and disturbance matrices and $x, u$ and $d$ are system control and disturbance vectors.

Power system model-I:

$$
\begin{aligned}
{\left[X_{1}\right.} & ]^{T}=\left[\begin{array}{l}
\Delta f_{1} \Delta P_{t 1} \Delta P_{g 1} \Delta f_{2} \Delta P_{t 2} \Delta P_{g 2} \Delta P_{t i e 12} A C E_{1} A C E_{2}
\end{array}\right] \\
{\left[U_{1}\right] } & =\left[\begin{array}{ll}
u 1 & u 2
\end{array}\right], \quad\left[D_{1}\right]=\left[\begin{array}{ll}
\Delta P_{d 1} & \Delta P_{d 2}
\end{array}\right]
\end{aligned}
$$

Power system model-II

$$
\begin{aligned}
& {\left[X_{2}\right]^{T}=\left[\Delta f_{1} \Delta P_{t 1} \Delta P_{g 1} \Delta f_{2} \Delta P_{t 2} \Delta P_{g 2} \Delta P_{t i e 12} A C E_{1} A C E_{2} \Delta P_{d c}\right]} \\
& {\left[U_{2}\right]=\left[U_{1}\right], \quad\left[D_{2}\right]=\left[D_{1}\right]}
\end{aligned}
$$

State equations:

From the transfer function block diagram shown in Figure 1, the following equations are obtained:

$$
\begin{aligned}
& \dot{x}_{1}=-\frac{1}{T_{p 1}} x_{1}+\frac{K_{p 1}}{T_{p 1}} \dot{x}_{2}-\frac{K_{p 1}}{T_{p 1}} x_{7}-\frac{K_{p 1}}{T_{p 1}} \Delta P_{d 1} \\
& \dot{x}_{2}=-\frac{1}{T_{t 1}} \dot{x}_{2}+\frac{1}{T_{t 1}} x_{3}
\end{aligned}
$$

$$
\begin{aligned}
& \dot{x}_{3}=-\frac{1}{R_{1} T_{g 1}} \dot{x}_{1}-\frac{1}{T_{g 1}} x_{3}+\frac{1}{T_{g 1}} u_{1} \\
& \dot{x}_{4}=-\frac{1}{T_{p 2}} x_{4}+\frac{K_{p 2}}{T_{p 2}} x_{5}+\frac{K_{p 2}}{T_{p 2}} x_{1}-\frac{K_{p 2}}{T_{p 2}} \Delta P_{d 2} \\
& \dot{x}_{5}=-\frac{1}{T_{t 2}} x_{5}+\frac{1}{T_{t 2}} x_{6} \\
& \dot{x}_{6}=-\frac{1}{R_{2} T_{g 2}} x_{4}-\frac{1}{T_{g 2}} x_{6}+\frac{1}{T_{g 2}} u_{2} \\
& \dot{x}_{7}=2 \pi T^{0} x_{1}-2 \pi T^{0} x_{3} \\
& \dot{x}_{8}=B_{1} x_{1}+x_{7} \\
& \dot{x}_{9}=B_{2} x_{4}-x_{7}
\end{aligned}
$$

From the above equations, System, control and disturbance matrices can be obtained as given below:

State matrix 'A', Control matrix 'B', and disturbance matrix $\Gamma$ for power system model-I are as follows below. The same matrices can be obtained for the power system model-II.

$$
A=\left[\begin{array}{ccccccccc}
-1 / T p 1 & K p 1 / T p 1 & 0 & 0 & 0 & 0 & -K p 1 / T p 1 & 0 & 0 \\
0 & -1 / T t 1 & 1 / T t 1 & 0 & 0 & 0 & 0 & 0 & 0 \\
-1 / R 1 T g 1 & 0 & -1 / T g 1 & 0 & 0 & 0 & 0 & 0 & 0 \\
0 & 0 & 0 & -1 / T p 2 & K p 2 / T p 2 & 0 & K p 2 / T p 2 & 0 & 0 \\
0 & 0 & 0 & 0 & -1 / T t 2 & 1 / T t 2 & 0 & 0 & 0 \\
0 & 0 & 0 & -1 / R 2 T g 2 & 0 & 1 / T g 2 & 0 & 0 & 0 \\
2 \pi T^{0} & 0 & 0 & -2 \pi T^{0} & 0 & 0 & 0 & 0 & 0 \\
B 1 & 0 & 0 & 0 & 0 & 0 & 0 & 0 & 0 \\
0 & 0 & 0 & B 2 & 0 & 0 & 0 & 0 & 0 \\
& & & & & & & &
\end{array}\right]
$$$$
B=\left[\begin{array}{cc}
0 & 0 \\
0 & 0 \\
1 / T g_{1} & 0 \\
0 & 0 \\
0 & 0 \\
0 & 1 / T g_{2} \\
0 & 0 \\
0 & 0 \\
0 & 0
\end{array}\right]
$$$$
\Gamma=\left[\begin{array}{cc}
-K p_{1} / T p_{1} & 0 \\
0 & 0 \\
0 & 0 \\
0 & -K p_{2} / T p_{2} \\
0 & 0 \\
0 & 0 \\
0 & 0 \\
0 & 0 \\
0 & 0
\end{array}\right]
$$

The area control error for area-1 is defined as:

$$
A C E_{1}=\Delta P_{t i e 1}+B_{1} \Delta f_{1}
$$

and the feedback control for Area-1 takes the form

$$
u_{1}=-K_{1}(s) A C E_{1}
$$

where $K_{1}(s)$ is the local LFC controller for area-1.

According to (Tan 2009,2010), a decentralized controller can be designed assuming that there are no tie-line power flows, In this case the local feedback control will be

$$
u_{1}=-K_{1}(s) B_{1} \Delta f_{1}
$$

\section{A control scheme for an interconnected power system}

\subsection{Tuning of AGC parameter}

The AGC regulator has the objective to minimize area control error (Xue et al. 2007). The AGC regulators 


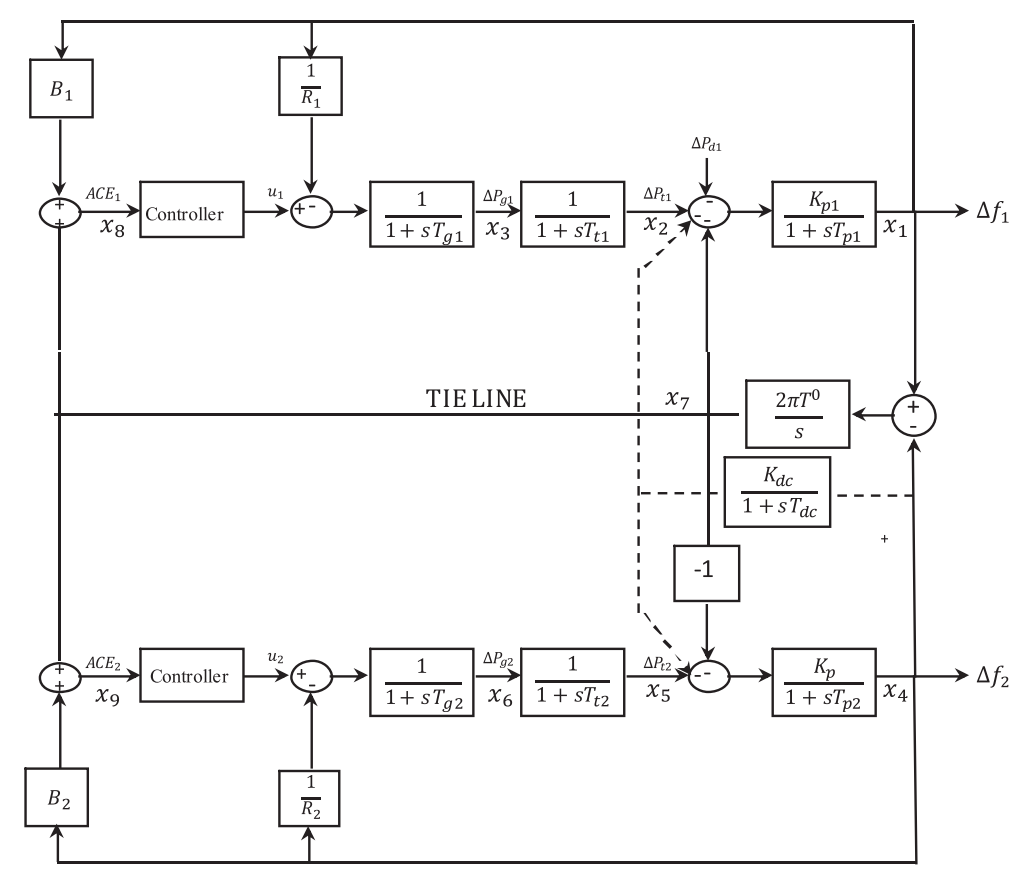

Figure 1 Transfer function model of power system.

having single output as a control signal based on PID is given below;

$$
u(t)=K_{P}\left[e(t)+\frac{1}{T_{i}} \int_{0}^{t} e(\tau) d \tau+T_{d} \frac{d e(t)}{d t}\right]
$$

where $u(t)$ is the control input for governor, $\mathrm{e}(\mathrm{t})$ the error, The tuning process of PID controller gain is done by Ziegler and Nichols (ZN) method (Asttrom \& Hagglund 1995). The proportional, integral and derivative gains are calculated for the critical ultimate gain, $\mathrm{Ku}$ and oscillation of ultimate time period, $\mathrm{Tu}$. These gains are shown below in Table 1.

\subsection{Genetic algorithm}

The genetic algorithm is a nature inspired optimization technique (Goldberg 1989). There are some sequential steps to be followed in developing the GA for automatic generation control. The Chromosomes Structure is built up with the initial set of random population in the form chromosomes which consists of genes as binary bits. These binary bits are then decoded to give proper string

Table 1 Gains of PID controller

\begin{tabular}{cccc}
\hline Controllers & Proportional gain & Integral gain & Derivative gain \\
\hline$P$ & $0.5 \mathrm{Ku}$ & & \\
PI & $0.4 \mathrm{Ku}$ & $0.8 \mathrm{Tu}$ & \\
PID & $0.6 \mathrm{Ku}$ & $0.5 \mathrm{Tu}$ & $0.12 \mathrm{Tu}$ \\
\hline
\end{tabular}

for optimization. The new population are regenerated which is to be converged at global optimum by the specified selection, crossover and mutation operators. Elitism is applied to save and use previously found best partner in subsequent fittest generation of population.

The processes stop as soon as convergence criterion is satisfied.

The flow chart of the GA algorithm used in this work is shown in Figure 2.

\subsection{Particle Swarm Optimization (PSO)}

Particle swarm optimization (PSO) is a population-based stochastic optimization technique which is based on the social behavior of bird flocking, fish schooling and swarming theory (Kennedy \& Eberhart 1995; Eberhart \& Kennedy 1995). In the PSO method, a swarm consists of a set of individuals named as particles are specified by their position and velocity vectors $\left(\mathrm{x}_{\mathrm{i}}(\mathrm{t}), \mathrm{v}_{\mathrm{i}}(\mathrm{t})\right)$ at each time. In an $n$-dimensional solution space, each particle is treated as an $n$-dimensional space vector and the position of the $\mathrm{i}^{\text {th }}$ particle is presented by $x_{i}=\left[x_{i}(1), x i(2), \ldots, x i(n)\right]$; then it flies to a new position by the velocity represented by $v_{i}=$ $\left[\mathrm{v}_{\mathrm{i}}(1), \mathrm{v}_{\mathrm{i}}(2), \ldots, \mathrm{v}_{\mathrm{i}}(\mathrm{n})\right]$. The best position for $\mathrm{i}^{\text {th }}$ particle represented by $\mathrm{p}_{\text {best }, \mathrm{i}}=\left[\mathrm{p}_{\text {best }, \mathrm{i}}(1), \mathrm{p}_{\text {best } \mathrm{i}}(2), \ldots, \mathrm{p}_{\text {best } \mathrm{i}}(\mathrm{n})\right]$ is determined according to the best value for the specified objective function and this global best position is represented as $g_{b e s t}=\left(g_{b e s t}, 1, g_{b e s t}, 2, \ldots, g_{b e s t}, n\right)$. For the next iteration, the position $\mathrm{x}_{\mathrm{ik}}$ and velocity $\mathrm{v}_{\mathrm{ik}}$ corresponding to 


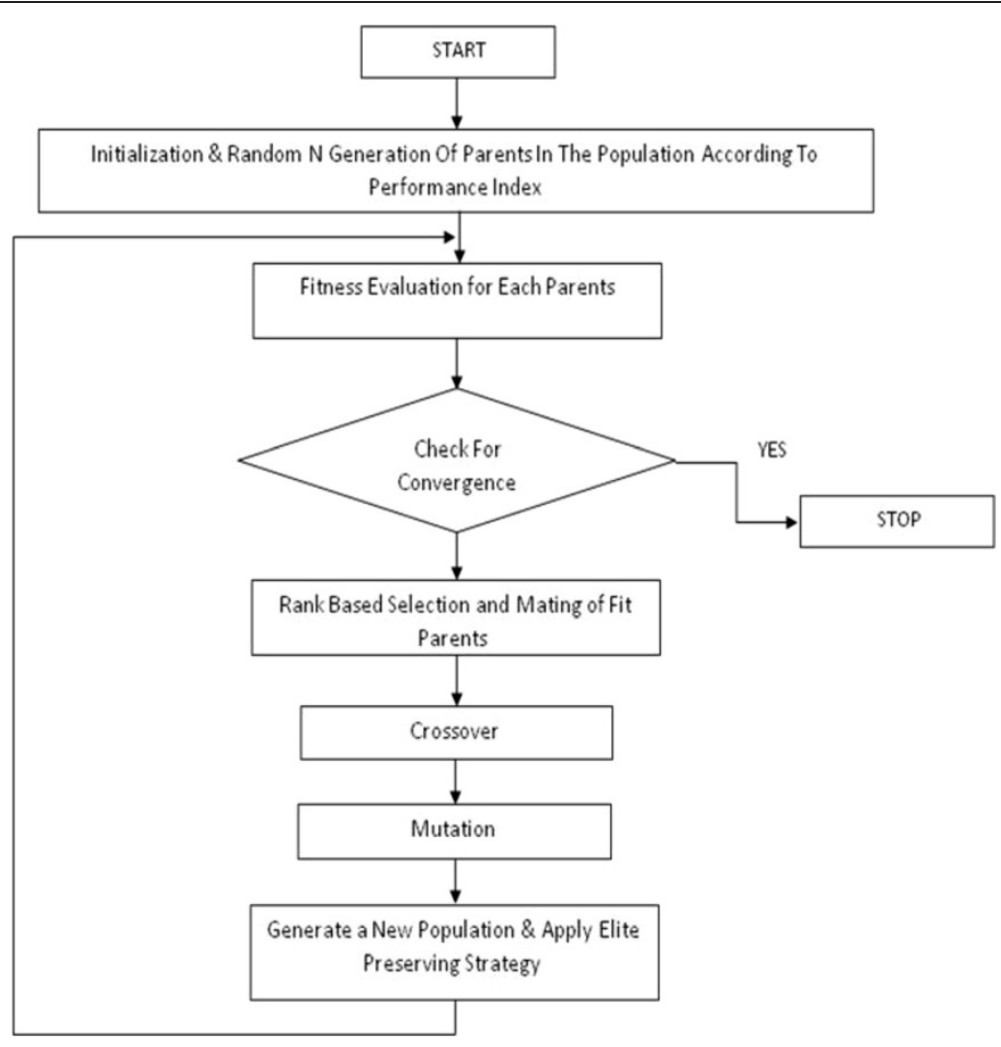

Figure 2 Flowchart of GA based optimization technique.

the $\mathrm{k}^{\text {th }}$ dimension of $\mathrm{i}^{\text {th }}$ particle are updated using the following equations:

$$
\begin{aligned}
v_{i k}(t+1)= & w \cdot v_{i k}+c_{1} \cdot \operatorname{rand}_{1, i k}\left(p_{\text {best }, i k}(t)\right) \\
& +c_{2} \cdot \operatorname{rand}_{2, i k}\left(g_{\text {best }, k}(t)-x_{i k}(t)\right) \\
x_{i, k}(t+1)= & x_{i k}(t)+v_{i k}(t+1)
\end{aligned}
$$

where $\mathrm{i}=1,2, \ldots, \mathrm{n}$ is the index of particles, $\mathrm{w}$ is the inertia weight, $\operatorname{rand}_{1, \mathrm{ik}}$ and $\operatorname{rand}_{2, \mathrm{ik}}$ are random numbers in the interval $\left[\begin{array}{ll}0 & 1\end{array}\right], c_{1}$ and $c_{2}$ are learning factors, and $t$ represents the iterations.

The flow chart of PSO as implemented for optimization is shown in Figure 3.

\section{Simulation results and discussion}

The dynamic responses of various system states of interconnected decentralized power system are obtained for AGC regulators designed using PID, GA and PSO. The simulation work is carried out using MATLAB software with numerical data shown in appendix A. In this paper both AC tie-line and parallel AC/DC tie-line as area interconnection are considered for the investigations. The time responses are plotted for various system states with implementation of designed AGC regulators considering $1 \%$ load perturbation in area-1. The Figures 4 and 5 show the dynamic responses of the frequency deviations in area- 1 and area- 2 respectively. The investigations of these plots inferred that with PSO controller, the oscillation, overshoot decreases as compared with GA and PID controller and also the settling time is faster in the case of time response with PSO with AC/DC tie-line compared to those offered by GA and PID. Figure 6 represents the tie-line power flow deviation between the two areas. The analysis reveals that the proposed controllers are capable to mitigate the deviations in tie-line power flows. The PSO controller has the superiority to the GA and PID in terms of over shoots and settling time. The Figures 7 and 8 are plotted for the area control error for area $1 \& 2$ respectively, the Figure 7 shows that the PSO controller has the best over shoot and settling time. The Figure 8 shows that the overshoot and settling time with GA controller is comparable with PSO and PID.

\section{Conclusion}

The AGC regulators are designed using PID, GA and PSO for two-area interconnected decentralized power 

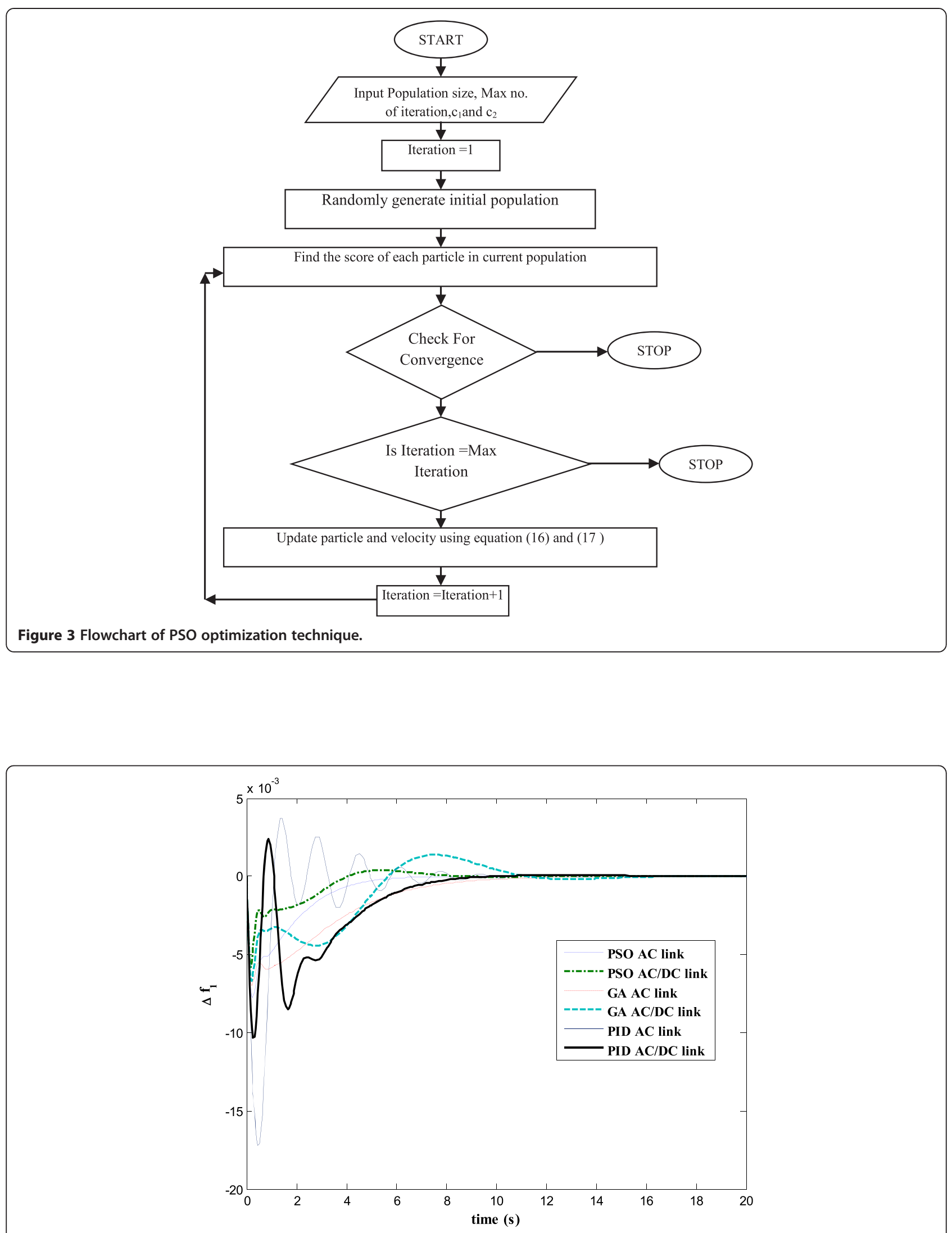

Figure 4 Dynamic response for $\Delta f_{1}$. 


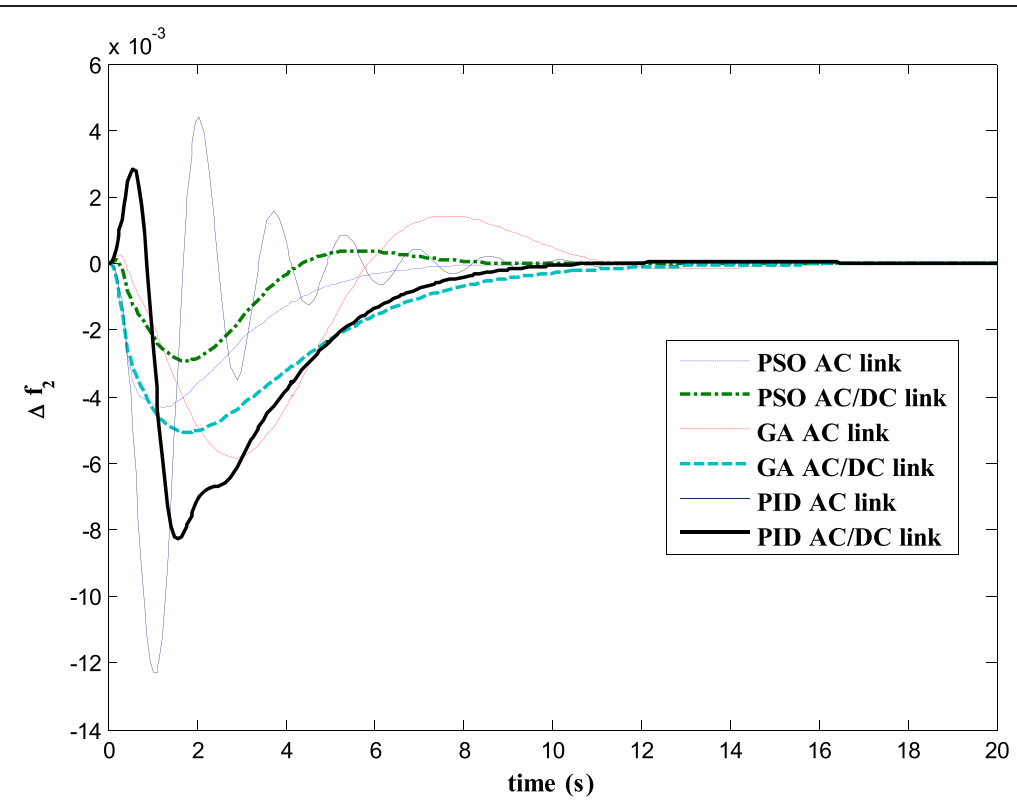

Figure 5 Dynamic response for $\Delta f_{2}$.

system. The area interconnections are considered as AC tie-line and parallel AC/DC tie-lines. Investigations of results are presented that inferred the superiority PSO controller in comparison to PID and GA. The comparisons have been made between the power system model-I and power system model-II consisting of AC tie-line and parallel AC/DC tie-line. The positive effect of DC link in parallel to AC tie-line is also clearly visible in the time response plots of all states with the designed regulators.

\section{Nomenclature}

$i$ subscript referring to area $i(i=1,2)$

$\Delta f_{i}$ frequency deviation of Area $(\mathrm{Hz})$

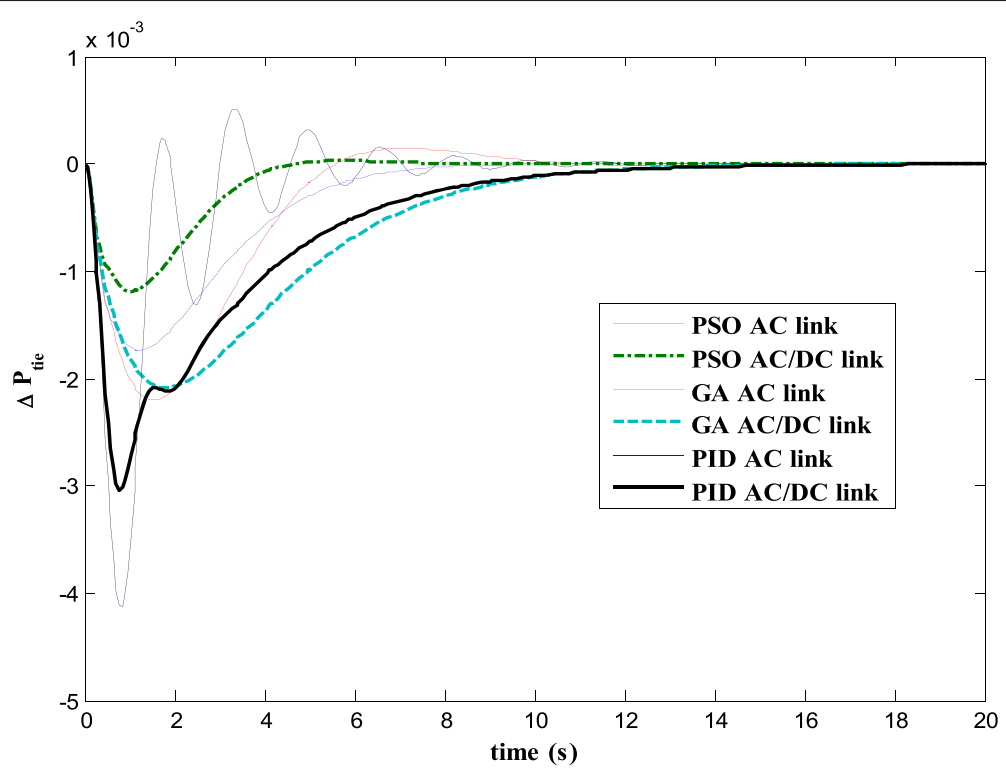

Figure 6 Dynamic response for $P_{\text {tie12. }}$. 


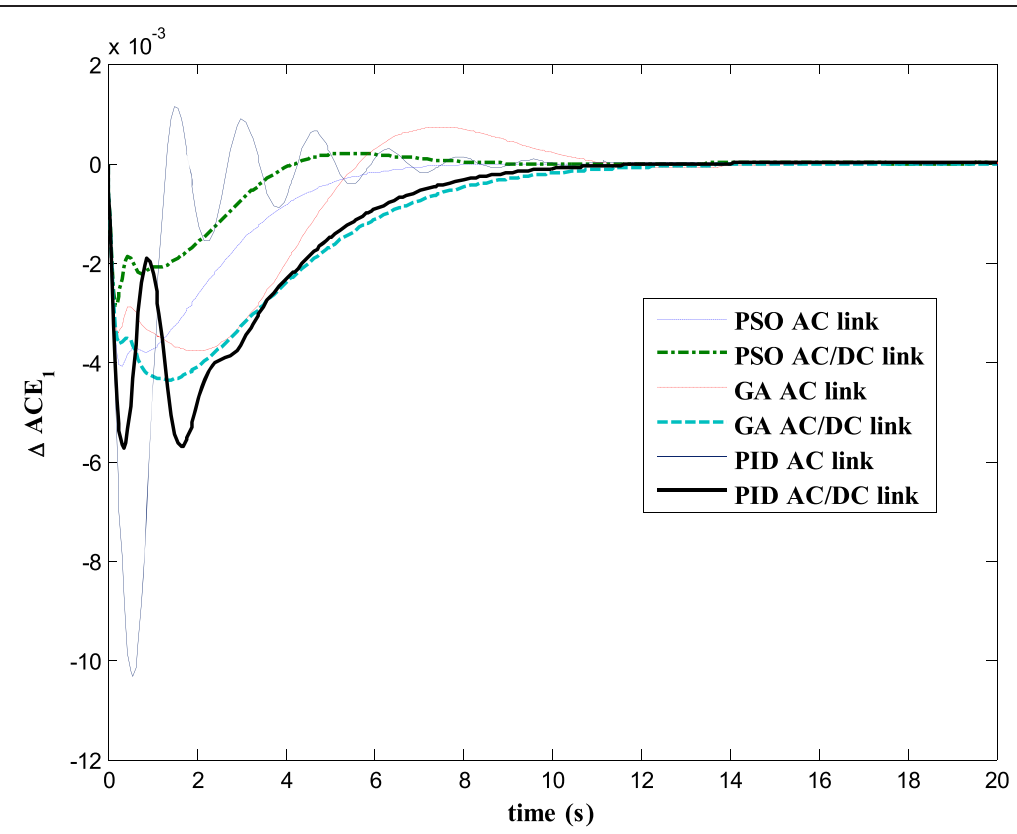

Figure 7 Dynamic response for $A C E_{1}$.

$A C E_{i}$ area control error,

$\Delta P_{t i}$ incremental change in power generation,

$\Delta \mathrm{P}_{\text {gi }}$ incremental change in governor valve position,

$\Delta P_{\text {tie }}$ tie-line power deviation,

$T_{g i}$ governor time constant for the ith area subsystem (s),

$T_{t i}$ turbine time constant for the ith area subsystem (s),

$T_{p i}$ plant model time constant for the ith area subsystem (s),
$T_{i j}$ synchronizing coefficient between the ith and jth area subsystem (p.u. MW),

$K_{p i}$ plant gain for the ith area subsystem, $R_{i}$ speed regulation due to governor action for the ith area subsystem,

$X_{i}(t)$ states of the $\mathrm{i}^{\text {th }}$ area subsystem,

$u_{i}(t)$ control input for the ith area subsystem.

ZN Ziegler and Nichols control method

ACE Area Control Error

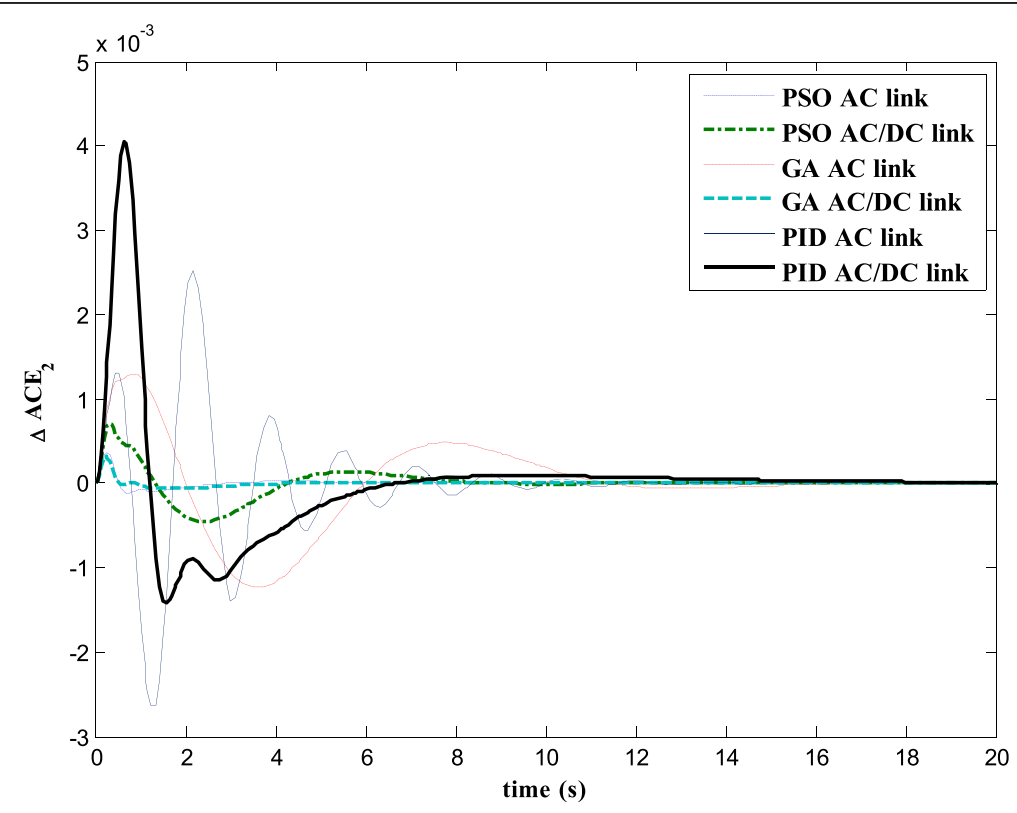

Figure 8 Dynamic response for $\mathrm{ACE}_{2}$. 


\section{Competing interests}

The authors declare that they have no competing interests.

\section{Authors' contributions}

AAH has studied intelligent optimization techniques such as "GA and PSO" and implemented for Decentralized AGC of two area interconnected power system. NH has supervised and reviewed the work carried out here in this paper to the best for the good understanding of the researchers. IB has fine tuned the modeling of the decentralized interconnected power system and simulation results. The authors have read and approved the final manuscript.

Received: 5 October 2014 Accepted: 4 December 2014

Published: 16 December 2014

\section{References}

Aldeen M (1991) Interaction modeling approach to distributed control with application to power systems. Int J Contr 53(5):1035-1054

Aldeen M, Marsh JF (1990) Observability, controllability and decentralized control of interconnected power systems. Int J Comput Elect Eng 16(4):207-220

Aldeen M, Marsh JF (1991) Decentralized proportional-plus-integral control design method for interconnected power systems. Proc Inst Elect Eng 138(4):263-274

Aldeen M, Trinh H (1994) Load frequency control of interconnected power systems via constrained feedback control schemes. Int J Comput Elect Eng 20(1):71-88

Astrom K, Hagglund T (1995) PID controller: theory, design, and tuning, 2nd edn. Instrument Society of American, North Carolina

Calovic MS (1984) Automatic generation control: decentralized area-wise optimal solution. Elect Power Syst Res 7(2):115-139

Eberhart R, Kennedy J (1995) A new optimizer using particle swarm theory, Proceedings of Sixth International Symposium, Micro Machine and Human Science, Nagoya, Japan., doi:10.1109/MHS.1995.494215 doi:10.1109/MHS.1995.494215\#blank

Elgerd OI, Fosha C (1970) Optimum megawatt frequency control of multi-area electric energy systems. IEEE Trans Power App Syst PAS-89(4):556-563

Fosha CE, Elgerd OI (1970) The megawatt frequency control problem: a new approach via optimal control theory. IEEE Trans Power App Syst PAS-89 (4):563-577

Goldberg DE (1989) Genetic Algorithms in Search, Optimization, and Machine Learning, 1st edn. Addison-Wesley Publishing Company Inc, U.S.A

Kawabata H, Kido M (1982) A decentralized scheme of load frequency control power system. Elect Eng Japan 102(4):100-106

Kennedy J, Eberhart R (1995) Particle swarm optimization, Proceedings of IEEE International Conference. Neural Netw 4:1942-1948

Kumar A, Malik OP, Hope GS (1985) Variable-structure-system control applied to AGC of an interconnected power system. Proc Inst Elect Eng C132(1):23-29

Kumar A, Malik OP, Hope GS (1987) Discrete variable-structure controller for load frequency control of multi-area interconnected power system. Proc Inst Elect Eng C134(2):116-122

Park YM, Lee KY (1984) Optimal decentralized load frequency control. Elect Power Syst Res 7(4):279-288

Quazza G (1966) Non-interacting controls of interconnected electric power systems. IEEE Trans Power App Syst PAS-85(7):727-741

Shayeghi H, Shayanfar HA, Malik OP (2007) Robust decentralized neural networks based LFC in a deregulated power system. Electr Power Energ Syst 47:241-251

Sudha KR, Vijaya Santhi R (2011) Robust decentralized load frequency control of interconnected power system with Generation Rate Constraint using Type-2 fuzzy approach. Electr Power Energ Syst 33:699-707

Tan W (2009) Tuning of PID load frequency controller for power systems. Energ Convers Manag 50:1465-1472

Tan W (2010) Unified tuning of PID load frequency controller for power systems via IMC. IEEE Trans Power Syst 25(1):341-350

Tan W (2011) Decentralized load frequency controller analysis and tuning for multi-area power systems. Electr Power Syst Res 52:2015-2023

Tan W, Zhou H (2012) Robust analysis of decentralized load frequency control for multi-area power systems. Elect Power Syst Res 43:996-1005

Xue D, Chen YQ, Atherton DP (2007) Linear feed back control: analysis and design with MATLAB. Society for Industrial and Applied Mathematics, Philadelphia

Yang TC, Cimen H, Zhu QM (1998) Decentralised load-frequency controller design based on structured singular values. Proc Inst Elect Eng C145(1):7-14
Yang TC, Ding ZT, Yu H (2002) Decentralised power system load frequency control beyond the limit of diagonal dominance. Int J Elect Power Energy Syst 24(3):173-184

doi:10.1186/2193-1801-3-744

Cite this article as: Ibraheem et al:: Decentralized automatic generation control of interconnected power systems incorporating asynchronous tie-lines. SpringerPlus 2014 3:744.

\section{Submit your manuscript to a SpringerOpen ${ }^{\odot}$ journal and benefit from:}

- Convenient online submission

- Rigorous peer review

- Immediate publication on acceptance

- Open access: articles freely available online

- High visibility within the field

- Retaining the copyright to your article

Submit your next manuscript at $>$ springeropen.com 